\title{
Framing the Mobile Phone: The Psychopathologies of an Everyday Object
}

\author{
lain MacRury ${ }^{1}$ \\ Bournemouth University, UK \\ Candida Yates ${ }^{2}$ \\ Bournemouth University, UK
}

\section{doi: 10.5937/comman11-11517}

Abstract: This article proposes that the affective processes that shape our relationship to the world of digital consumption and communication can be illuminated further when viewed through a lens of object relations psychoanalysis. We focus on the use of the mobile phone as both an object in the world and of the psyche in order to reflect upon its uses as an evocative object that shapes the psychosocial boundaries of experience in everyday life. We argue that in contrast to the concepts of interpersonal communication that can be found in some domains of popular culture and in communication studies, object relations psychoanalysis can be usefully deployed in order to explore the unconscious attachments that develop in relation to consumer objects, allowing for the complexity of feeling and reflection that may emerge in relation to them and the potential spaces of the mind. The mobile phone's routine uses and characteristics are widely understood. At the same time, the mobile phone invites critical reflections that identify a paradoxical object of both creative and pathological use. Such reflexivity includes the mobile's relationship to the complexity of psychosocial experience within the contemporary cultural moment. Applying the ideas of psychoanalysts Donald Winnicott, Thomas Ogden and Christopher Bollas, we argue that one explanation for why the mobile phone continues to attract not only enthusiastic cultural commentary but also a degree of apprehension across academic and popular-discursive settings can be found in its capacity to both disrupt and connect as an object of attachment and as a means of unconscious escape.

Keywords: transitional object, potential space, pathology, mobile phone, object relations psychoanalysis

\footnotetext{
1 Contact with author: imacrury@bournemouth.ac.uk.

2 Contact with author: cyates@bournemouth.ac.uk.
} 


\section{Mobile Anxieties: Overview of a Psychosocial Object}

The mobile phone $\mathrm{e}^{3}$ is a complex cultural and technical object; singular, in that it can be held in the palm of the hand, but also multiple in scope, in terms of its functionality and in the personal and social significances attached to it. This technology forms at once a disruptive and containing intervention in contemporary psychosocial experience and a core component in shifts towards a more mobile society (Elliot \& Urry, 2010). The mobile phone provides a major vector for grasping contemporary experience (cognitively, emotionally and practically) and it provokes some disruptions in the patterning of psychosocial and cultural life. Such disruptions invite anxiety and commentary, producing thinking and reflective analyses across public discourses that we propose are inflected by the unconscious emotional-intimate properties of the mobile-asobject. As we discuss, object relations psychoanalysis provides a highly evocative set of concepts to explore the contemporary experience of the mobile phone, which is bound up in the unconscious processes of object relating as a mode of experiencing the self and of engaging with the world.

The mobile (as we shall call it from here on) remains in the cultural limelight, not just through promotions-driven marketing, with slogans such as, "This changes everything", and "Inspire the World, Create the Future", produced by major manufacturers such as, Apple, Samsung and Microsoft, LG and Huawei, and via network providing retailers such as Vodaphone, EE and " 3 ", but across news, comment and broader cultural conversations. The mobile provides an object for reflective and sometimes obsessive-seeming commentary across media. Recent headlines indicate typical preoccupations including: "Mobile phone addiction ruining relationships" (Alleyne, 2012), "How women love their mobile phones... more than their boyfriends" (Daily Mail Reporter, 2009), "Just Thinking About Your Cell Phone Makes You More Selfish" (Garber, 2012), "Mobile phones have changed the world, for better or worse" (Clark, 2015), "Do you have a love/hate relationship with your phone?" (Kunst, 2012), "Mobile addict parents guilty of child neglect" (Bingham, 2012) and "Nomophobia

3 For this paper we have adopted the phrase "mobile phone" rather than the ostensibly more modern "smartphone" to refer to the devices under our investigation. Widespread usage of the term "smartphone" has largely been the result of journalistic and marketing rhetoric rather than clear demarcations between hardware and software platforms. As Kang \& Son (2009: 919) note, "there is no clear industry-standard definition of smartphone". Consumers themselves are unlikely to talk about 'losing their smartphone', whereas 'where on earth did I leave my mobile?' is a modern cri de cour. 
affects majority of UK" (Royal Mail, 2008). These titles and their prevalence are partly a function of 'clickbait' culture, yet they also offer a sense that mobiles provide a recurrently anxious focus for lifestyle commentary, with the final one referencing a 'syndrome' called "nomophobia", to capture the idea that people fear losing their mobile phones.

\section{Mobile Disruptions: Context and Critique}

The mobile induces a more complex-seeming sociality, widening the communicative arrays and practical intersections that generate the global and local "networked individualism" that is characteristic of the contemporary period (Castells, 2007). In a more psychological register, the mobile is assertively individualistic in terms of its use. Connective as they are, mobiles are rarely shared, as such. An individual's phone clusters and invites personal attention. It stands as both a conduit for and an object of excitement; a mirror and a lamp, projecting and receiving informatic and affective material; a stage and a screen for everyday engagements and emotional attachments. Personal in this sense, the mobile is highly personalised via account settings, passwords and fingerprint recognition. The phone is also personalising, in part via the evolving (mobile) digital footprints and signatures of users - data and surveillance-based algorithmic constructions, binding 'persons' to mobile personae.

The symbolic and material significance is linked to wider power relations within the contemporary historical moment or "conjuncture" ${ }^{4}$ (Hjorth, Burgess $\&$ Richardson, 2012). The mobile phone brings together key concerns that address notions of power and the construction of the subject in culture and it is helpful to think about the mobile as a "cultural formation" that shapes and is shaped by the affective experience of cultural life. Put simply, the mobile phone represents a developing inflection within contemporary structures of feeling. The mobile raises questions about identity and associated notions of agency, creativity and desire. Notably, the mobile opens up new capacities, facilitating modes of intimacy that are at once immediate and yet can seemingly transcend the limits of time and space (Díaz \& Ekman, 2011; Hjorth \& Lim, 2012).

On the other hand, the impulse to keep checking one's phone continues to be framed as a symptom of the anxious neoliberal subject of late modern capitalism (Giroux, 2015; Fisher, 2009, 2014; Elliot, 1996). Whilst contem-

\footnotetext{
4 As with earlier studies of the Sony Walkman as an object of cultural consumption (Du Gay et al., 2013).
} 
porary digital culture creates opportunities for privatised modes of escape and self-experience, it also contributes to the process of emotional governance and the unpaid labour of the neoliberal workplace, where one is continually available online (Serrano-Puche, 2015). So just as the mobile facilitates complex and fluid relationships it can also be viewed as an object that is used defensively in order to retreat into regressive psychological positions in which communication with the outside world can feel curtailed or surveilled, structured by globalised software companies such as Google and Microsoft.

\section{An Evocative Object}

We propose that one explanation for why the mobile retains its place as an object of fascination and as a continuing focus for thinking (as well as a source of worry) across academic and popular-discursive settings can be found in a psychoanalytically informed examination of the uses of the mobile as an object in everyday life and its role in shaping subjectivity. Beyond its cultural and practical-functional significance, the mobile carries powerful unconscious importance. Specifically, as an object, the mobile often serves as an index for the work (and play) of social, emotional and personal attachment (Bowlby, 2008; Winnicott, 1971). The mobile is a unique intervention in the endeavours of human relating and not (just) a disruptive new communications technology. The mobile forms for us, we suggest, a powerful unconscious representation of connection and disconnection, one that evokes thinking, analysis and commentary and conveys feelings that are redolent of the Zeitgeist.

We argue that object relations psychoanalysis has a useful role to play in helping to contextualise some of the concerns about the specific "problems" that have emerged around mobile phone consumption and use. As we have seen, in popular discourse, the enthusiastic and creative use of the mobile phone is also often shadowed by discourses identifying addiction, relationship breakdown, illiteracy, solipsistic mobile privatism and related, emergent psychosocial problems. We propose that the mobile has become, culturally, a particular kind of "evocative object", following Christopher Bollas's (2009) phraseology, also echoed in the work of Sherry Turkle (2011b). As we discuss, the mobile has become uniquely evocative of the present conjuncture in such a way as to inflect elements in the public discourse, but also in the sense that, as Bollas puts it, it forces us "to think and think again" (Bollas, 2009: 85-6) about psychosocial experience. 


\section{An Object for Psychoanalysis}

Psychoanalytical ideas offer perspectives to enrich some of the main theoretical framings through which academic analysis seeks to understand and evaluate mobile cultures and human relations. There has of late been a turn to object relations psychoanalysis (Bainbridge \& Yates, 2014) that emphasises the realm of maternal phantasy within a relational paradigm that places the processes of relating to objects at its heart and therefore offers a relevant set of emphases for thinking about one's relationship to the mobile phone. The 'object relations' approaches developed by, amongst others, Melanie Klein (1937, 1946) and Donald Winnicott (1971), and further extended and explored by Thomas Ogden (1992) offer a useful idiom for thinking about the mobile. Winnicott, in particular, stressed the importance of attachments, ${ }^{5}$ and of the first relationship between the infant and its mother for the shaping of selfhood and identity.

Object relations perspectives help to capture the complexities of networked intersubjective life whilst holding on to an account of interior experience in a unique way. As Ogden argues:

"Object relations theory, often erroneously thought to be an exclusively interpersonal theory that diverts attention from the unconscious, [is] in fact fundamentally a theory of unconscious internal object relations in dynamic interplay with current interpersonal experience." (Ogden, 1986: 131)

This strand of psychoanalytic thinking offers an understanding of 'objects' and 'spaces' that is well equipped for grasping the instability and paradoxical qualities of the mobile and its uses, specifically, as we will now propose, via Winnicott's conceptions of potential space and transitional objects.

\section{Paradoxes and "Transitional Objects"}

Frequently identified as "paradoxical" (Eco, 2014; Fortunati, 2002; Fortunati \& Taipale, 2014; Elliot \& Urry, 2010), the mobile's phenomenological presence nags at functional analytical categories. The mobile is so frequently identified as "paradoxical" because it plays at boundaries. At the levels of practice and the imagination, the mobile mixes up presence and absence, me/not-

\footnotetext{
5 Despite some tensions in their relationship, Winnicott was influenced by Bowlby's attachment theory, developed in the early 1950s (Kahr, 2016; Bowlby, 2008) - an approach that has continuing relevance and which in turn has influenced Didier Anzieu and other non-Lacanian psychoanalytic theorists.
} 
me, subject and object; and it seems to mix these things up in us. Such mixing can provoke anxieties. As observed, the mobile is continuous with us, precious, and, in some sense a McLuhanesque "extension" (McLuhan, 1964). At the same time, it also stands as a distinct "object".

After exploring and clarifying the meanings and uses of D. W. Winnicott's concepts of the "transitional object" and the "potential space", we will identify some of the varieties of pathological distortion experienced in them - distortions also frequently evoked in discourses around the mobile phone.

\subsection{The "Transitional Object"}

Typically working by analogy with Winnicott's (1971) approach (one that is based on nursery and clinical work, (Kahr, 2016)), the mobile can be seen as having some similarities with the "special" objects found and, in an important sense, "created" (Winnicott, 1971: 96) by young children in the play of development and becoming, the fabled favourited toy or piece of material. As Winnicott sets it out, for the baby, the physical object concerned in this work hardly matters: "perhaps a bundle of wool or the corner of a blanket or eiderdown, or a word or tune, or a mannerism," but (nevertheless) the transitional object "becomes vitally important to the infant" (Winnicott, 1971:2; see also Kahr, 2016 $)$. The object is important in the formation of the self and in the separation and connection between the object-world and the world of internal objects, a "third part of the life of a human being, a part that we cannot ignore ....an intermediate area of experiencing, to which inner reality and external life both contribute" (Winnicott, 1971: 2).

The transitional object indexes a prefiguring ground for some of the work of separation and attachment (Bowlby, 2008), but also for an enduring existential frame stretching beyond infancy. "The use of an object symbolises the union of two now separate things, baby and mother, at the point in time and space of the initiation of their state of separateness" (Winnicott, 1971: 97, Italics in original). The transitional object, and the developmental achievements entailed in the use made of this object ${ }^{7}$ are, subsequently, vitally important to human development - to living. As Winnicott outlines:

\footnotetext{
${ }^{6}$ Kahr refers to Arthur Miller's children's story Jane's Blanket as a well rendered account of the transitional object. Winnicott himself mentions Charles M Schultz's Peanuts cartoons and A. A Milne's Winnie the Pooh as helpful cultural reference points.

As Winnicott tries to clarify: "what I am referring to in this part of my work is not the cloth or the teddy bear that the baby uses - not so much the object used as the use of the object" (Winnicott, 1971: xi).
} 
"I have introduced the terms "transitional objects" and "transitional phenomena" for designation of the intermediate area of experience, between the thumb and the teddy bear, between the oral erotism and the true object-relationship, between primary creative activity and projection of what has already been introjected, between primary unawareness of indebtedness and the acknowledgement of indebtedness." (Winnicott, 1971: 2)

The transitional object, and the use made of that object, ${ }^{8}$ is the beginning of "cultural experience" (Winnicott 1971: 100) but, also, an opening up of a space for highly valued, developmental achievements, that include: reciprocity, creativity and what he describes as "a capacity for concern" (Winnicott, 1963).

A final developmental element in this narrative is that the transitional object prefigures the attainment of another significant and paradoxical achievement: the capacity to be alone in the presence of the mother. This "capacity to be alone" (Winnicott, 1958) marks a subtle specification for creative, independent and engaged living. In the intensively connected mobile world the fragile link between creative aloneness and psychosocial belonging remains a perennial theme, which is explored, for instance, in Sherry Turkle's Alone Together (2011), an echoic reframing of Riesman's classic The Lonely Crowd (1950) for a mobile-digital age. We suggest that, because of this ongoing thematic, there is a renewed resonance of "transitional objects" in the analytical conversation regarding mobiles within the frame of the present conjuncture.

We propose that the mobile phone is a kind of objectual ${ }^{9}$ realization of this conception of a "transitional object", a practical figuration of this "special", "first" object. As a major part of thinking about "culture" and experience, the mobile is also a prop in individuals' continuing dramatic enactment of another key idea: "potential space". The mobile phone enacts and dramatizes "potential space" and (as such) it invites interpretations that seek to analyse the (paradoxical) "potential space" spoken of in object relations psychoanalysis. As Ogden puts it:

"The transitional object is a symbol for this separateness in unity, unity in separateness. The transitional object is at the same time the infant (the om-

\footnotetext{
8 To underline, emphasis is given to, "not so much the object used as the use of the object" (Winnicott, 1971).

9 "Objectual" is a term deployed see Knorr (2008) and see also Woodward's highly relevant (2011) conceptiondefinition: "Objectual things are handled and used, powerfully combining embodied pragmatics with emotion, cultural myth and symbolism...” (Woodward, 2011: 367).
} 
nipotently created extension of himself) and not the infant (an object he has discovered that is outside of his omnipotent control). The appearance of a relationship with a transitional object is not simply a milestone in the process of separation-individuation. The relationship with the transitional object is as significantly a reflection of the development of the capacity to maintain a psychological dialectical process." (Ogden, 1992: 228)

What we propose is that when people talk about mobile phones, they are exploring psychological processes entailed in potential space. The discourse around mobiles is indexical to a deeper set of anxieties adumbrating experiences of, and capacities to experience, potential space.

\section{Exploring Mobile Transitions}

Some applications of the idea of "transitional objects" have set out to help think about media, material and cultural consumption (see, for example, Turkle 2011; 2013; Silverstone \& Hirsh, 1992; Hills, 2007; Woodward, 2011; Whitty \& Carr, 2003; Kuhn, 2013; Johnson, 2010). However, sometimes, the accounts that focus on the mobile phone underemphasise the unconscious dimension in favour of a more interpersonal conception of the use of mobiles as objects that focus on the here and now rather than evoking resonances with early infant experiences (Ling, 2007, drawing on Silverstone \& Hirsh, 1992; Ribak, 2009; Kullman, 2010; Johnson, 2010). These studies have applied the notion of the "transitional object" within an ethnographic framework that seeks to understand the place of technology within the delicate nexus of attachments, separations, and entanglements characteristic of specific social contemporary domains such as love (Johnson, 2010), family life (Ribak, 2009), school journeys (Kullman, 2010) and "adolescent emancipation" (Ling, 2007). In these cases, the mobile becomes a means in the practical and emotional management of separation and development. For example, Ling examines

"the dialectic nature of mobile phone use by teens. On the one hand it serves as a greatly extended umbilical cord or in the phrase of Roger Silverstone, a "transitional object" (Silverstone, Hirsch, \& Morley, 1991), but on the other hand it plays into the emancipation process of adolescents." (Ling, 2007: 61). 
Ribak (2009) extends the umbilical cord metaphor, but adds in the idea of "remote control", and situates the mobile in a set of triangular relationships marking the parent, technology and the child. Ribak makes a detailed and convincing analogy with the transitional object and yet ultimately rejects a too direct comparison on a number of practical grounds. Kullman's (2010) geographic approach adds a helpful Latourian twist, recognising that the mobile is but one component in an assemblage of transitional objects (bags, books, toys) used by tween children nervously navigating early journeys in third spaces between home and school and depending on flexible adaption between adult and child. She notes that "essential for this flexibility is the most common technology among children - the mobile phone" (Kullman, 2010: 837).

The conception of the mobile as a "transitional object" now colours contemporary popular discourse. For instance, business guru, Margaret Heffernan (2013) writes:

"The cell phone has become the adult's transitional object, replacing the toddler's teddy bear for comfort and a sense of belonging. We clutch phones to show that we do know at least one other person - that we might look solitary but we have connections. We are important because we might get called about something crucial - or, at least, non-trivial. We count in the world. Our insecurity may be laughable but our response isn't." (Heffernan, 2013)

Aaron Balick (2016), who has written extensively on digital cultures from an object relations perspective (2013), writes in his insightful blog, in more nuanced terms, that, as a culture, we, "have re-invented the transitional object - only rather than a furry blanket or a teddy bear, it's a smartphone". He adds some thought-provoking advice for his readers:

"So next time you absentmindedly reach into your pocket for your smartphone - pause for a second and think. What am I actually searching for? You may find that at bottom there's a niggling sense of insecurity - and you just want to check to make sure someone else on the planet is thinking of you." (Balick, 2016) ${ }^{10}$

\footnotetext{
${ }^{10} \mathrm{http} / / /$ www.aaronbalick.com/blog/checking-your-smartphone-again-its-an-object-of-emotional-supply/, accessed 10 December, 2016.
} 


\section{Potential Space: The Psychosomatic Underpinning for Attachment, Culture and Communication}

The idea of a transitional object is clearly an appealing one in the various contexts identified above. It offers an insight in ethnographic analyses (Ling, 2007; Kullman, 2010), even when important reservations are set down (Ribak, 2009). ${ }^{11}$ The observation of the transitional object typically highlights its character as an "intermediary" part of real world usage - correlating neatly with the phone's practical-communications functions. However, this vision can occlude the unconscious underpinning identified in the original literature and the psychoanalytic observation of transitional objects. It also understates the peculiar place of the object, its location in a fluid nexus of related conceptions, most notably Winnicott's ideas of transitional phenomena and potential space. As a result, when the metaphor is transplanted into everyday scenarios, some aspects of things identified as "transitional objects" suffer a diminution in meaning. The "transitional object" becomes, more straightforwardly, an intermediary object, either marking developmental stages (a prop in the transition to independence) or a point of connection in interpersonal relationships.

The unconscious component of experience in respect of the transitional object is at risk of being forgotten about. Sometimes, the transitional object becomes identified as a "regressive" object because it is associated with infancy but is used by adults. Yet, in Winnicott's conceptions, the transitional object is a component in normal, ongoing healthy development and is linked with lifelong "cultural" capacities and creative object relations. Furthermore, focusing on the object and its intermediary function, rather than on the (unconscious) use of the object, can occlude recognition of the pathological meanings and uses that may underlie the activities of intermediation. These misconceptions can arise if the object - as in the example of the mobile - is thought about independently of the connected ideas of transitional phenomena and potential spaces.

\footnotetext{
${ }^{11}$ Ribak qualifies the metaphor in a number of ways, partly linked to her focus on teenagers and parents, and concludes: "the mobile phone is not 'transitional' in the way teddy bears and blankets are, since it provides an actual link to the mother: it is less of a symbolic object and more, a means of communication" (Ribak, 2009: 192).
} 


\section{From Transitional Object to Potential Space}

In the object relations view, the transitional object's intermediary role is linked to and embedded within an interplay of both external and inner spaces of the self - so here we propose an attentiveness to psychoanalytical uses of the term that seek to acknowledge more fully the unconscious aspects of (transitional) experience. Winnicott indicates what he means by this:

"Of every individual who has reached the stage of being a unit with a limiting membrane and an outside and an inside, it can be said that there is an inner reality to that individual, an inner world that can be rich or poor and can be at peace or in a state of war." (Winnicott, 1971: 2)

To think about "inner and outer experiences", and "me-not-me experiences," an "area" is invoked (as it were) between inner (First) and outer (Second) areas:

"the third part of the life of a human being, a part that we cannot ignore, is an intermediate area of experiencing, to which inner reality and external life both contribute. It is an area that is not challenged, because no claim is made on its behalf except that it shall exist as a resting-place for the individual engaged in the perpetual human task of keeping inner and outer reality separate yet interrelated." (Winnicott, 1971:2)

He continues:

"I am concerned with the first possession", [i.e. the "transitional object" and, also and at the same time], "with the intermediate area between the subjective and that which is objectively perceived." (1971: 3 italics added)

The term, "area" is important here, as it underlines that the transitional object (and its use) represent and enact an incidence of and within a "space". Winnicott talks about this idea of an existential "resting place" within "being" and of the idea of "potential space", thereby indicating something of the basicontological value of experience in and of this space. Psychoanalyst, Robert Rodman clarifies:

"Experiences in the area of potential space allow us to have periods of rest from the struggle to draw lines between ourselves and others. ... There is a built-in strain in human life caused by the need to maintain a line that 
defines us as separate from others. This line need not confuse and exhaust the baby in possession of a transitional object, and a mother who understands his or her need for a particular kind of comfort. The resting place thus given continues to play the same role in the successive stages of human development." (Rodman, in Winnicott, 2005: xiv)

We propose that the mobile's capacity to represent and to index this "resting place" and the disruptions entailed to it is a notable component in our ongoing experience of neoliberal subjectivities, cultures and social milieus and the negotiation of meanings in these contexts.

Winnicott underlines that the transitional object cannot be, exclusively, the focus within this conceptual framing. It has a part to play, one that in terms of the object itself, recedes into the past, but which includes and is included in a legacy of capacities and dispositions linked to "transitional phenomena" and "potential space". As the child develops,

"the transitional object loses meaning, and this is because the transitional phenomena have become diffused, have become spread out over the whole intermediate territory between 'inner psychic reality' and 'the external world as perceived by two persons in common', that is to say, over the whole cultural field." (Winnicott 1971: 5)

Highly abstract (and "hypothetical") as it is, "potential space" allows us to apprehend a somatic inter-and intra-subjective achievement linked to the earliest phases of development (Ogden, 1986: 131). Its place in infancy does not relegate "potential space" to "the past". Nor does its origin in neonatal development render its contribution to experience, infantile or regressive. Instead, "potential space" remains a generative pre-condition that continues in growth, going on framing present (adult and maturational) psychosocial capacities and experiences - creative and re-creative, "ordinary" (Winnicott, 1971) and "human" (Ogden, 1992).

Potential space is always-already preliminary to development, yet it is also necessary to any future generativity. Its formation engenders within the development of any individual, a pre-forming within the emerging relationship that occurs "between the baby and the object (mother or part of mother)" (Winnicott, 1971:107). What we grasp, in "potential space", is something of the dynamic conditionality imbricating the emergence of subjective experience; one whose (primitive) legacy continues into and throughout the future life of the subject. 
It is both intermediation and the intimation of a frame for relationality. It opens up the ground against which any subjectivity that might become, must initially, be figured (out). This emergence is a core component of the experience of separation, the "phase of the repudiation of the object as not me, that is, at the end of being merged with the object" (Winnicott, 1971: 107). As such, "potential space" forms and informs the matrix-template through which experience (thoughts, feelings and symbols) become articulated (see Ogden, 1992). It is part of processes of detachment, setting the tone for future dialogic achievements: attachments and separations. It becomes, for Winnicott, the basis for our most valued capacities: playing, concentration, creativity, and "cultural" living (Winnicott, 1971: 95-110).

"Potential space" evokes an interstice and an interlude; peculiarly empty and full and linking being to becoming. As Winnicott puts it: "Potential space" is an "intermediate area of experiencing" (1971: 2) that lies between the inner world, "inner psychic reality" (1971: 5), and "actual or external reality" (1971: 41). This conception offers a grasp of a subtle unconscious dynamic, paradoxical connection-disconnection: "Potential space both joins and separates the infant (child, or adult) and the mother (object), it lies in the paradoxical moment where "continuity is giving place to contiguity" (Winnicott, 1971: 101).

Potential space can be understood, then, as a psychosomatic, unconscious underpinning for attachment, culture and communication - with, we suggest, the mobile functioning as a powerful enactor of, and vector for and within such capacities. This change of emphasis from primary attention upon the transitional object itself, places it within the nexus of unconscious experiencing facilitated as well as represented by the potential space. This shift of perspective also helps us to understand the discourse around mobile phones more fully. We propose that the prevalent conversation across a number of discursive areas about the mobile is not just to do with its characteristic similarity to the transitional object alone, but, instead is due to its taking a place in the cultural imagination that is unconsciously and practically evocative of the transitional object and potential space. As such, the mobile affords and can be understood as a means to reflect on, express and occasionally act out feelings and emotions linked to unconscious experience in these terms.

Put simply, the mobile phone becomes emblematic of and a useful way to think about our ongoing experience of connection and disconnection within the social world. As has been well documented, this social experience, which is 
characterised by risk (Beck, 1992) and the flux and change of liquid modernity (Bauman, 2007), also includes anxiety and anomie.

\section{Pathologies of Potential Space}

Alongside what might be called the "healthy", "life-enhancing" uses of transitional objects and potential space, there is also a recognition of obverses: an inhibition or seduction connoting either the under or exaggerated use of the object (Winnicott, 1971: 15-25). The pathological use of transitional phenomena may be expressed in relation to the emergence or non-emergence of creative capacities, failures in separation and the various instabilities that also characterise this "space" (Kahr, 1996, 2016; Spelman \& Thomson-Salo, 2014; Ogden, 1992). Winnicott (1971: 15-20) offers a valuable clinical vignette that helps to grasp the unconscious anxieties underpinning exaggerated or pathological use of a seeming-transitional object.

Following "a short clinical example of a boy's use of string", ${ }^{12}$ Winnicott (1971: 16) describes a 7-year-old boy who played obsessively with string. $\mathrm{He}$ discerned deep-seated concerns linked to anxiety about separation and a depressed mother. Winnicott concludes:

"String can be looked upon as an extension of all other techniques of communication. String joins, just as it also helps in the wrapping up of objects and in the holding of unintegrated material. In this respect string has a symbolic meaning for everyone; an exaggeration of the use of string can easily belong to the beginnings of a sense of insecurity or the idea of a lack of communication. In this particular case it is possible to detect abnormality creeping into the boy's use of string, and it is important to find a way of stating the change which might lead to its use becoming perverted." (Winnicott, 1971: 19)

We might say the same about mobiles - they invite us to look at them and they seem to evoke a sense of (all) other techniques of communication. As such, and in the face of, say, exaggerated use, we might recognise some aspect of perversion creeping into the use of this object, too. Winnicott's intimation (above) of such "perversion" is, we propose, connected to cultural concerns about psychosocial experience. As we argue, the mobile affords a means to express existential and unconscious anxieties.

${ }^{12}$ And here, we cannot but recall the old-fashioned telephone games played with cans and string. 


\section{Pathologies Examined and Exemplified}

Thomas Ogden has outlined ways of thinking about specific "pathologies of potential space" (Ogden, 1992). Healthy potential space can be fragile. It can even "collapse". Ogden's (1992) contribution is useful, then, in articulating something of the vicissitudes of such "collapses" and seeking to specify the characteristic dynamics of such pathologies. Ogden (1992) carefully articulates the ways that potential space can fail to fully sustain dialogical capacities for (object) relating between inner and outer experience. He describes the various disruptions in potential space, seeking to clarify Winnicott's account of potential space, and to examine patients' difficulties, while at the same time providing a useful proto-typology of disruptions in the formation and experience of transitional objects and potential spaces. This can be represented in a diagram (Fig 1.0), although, necessarily, any such representation simplifies the experiences being explored.

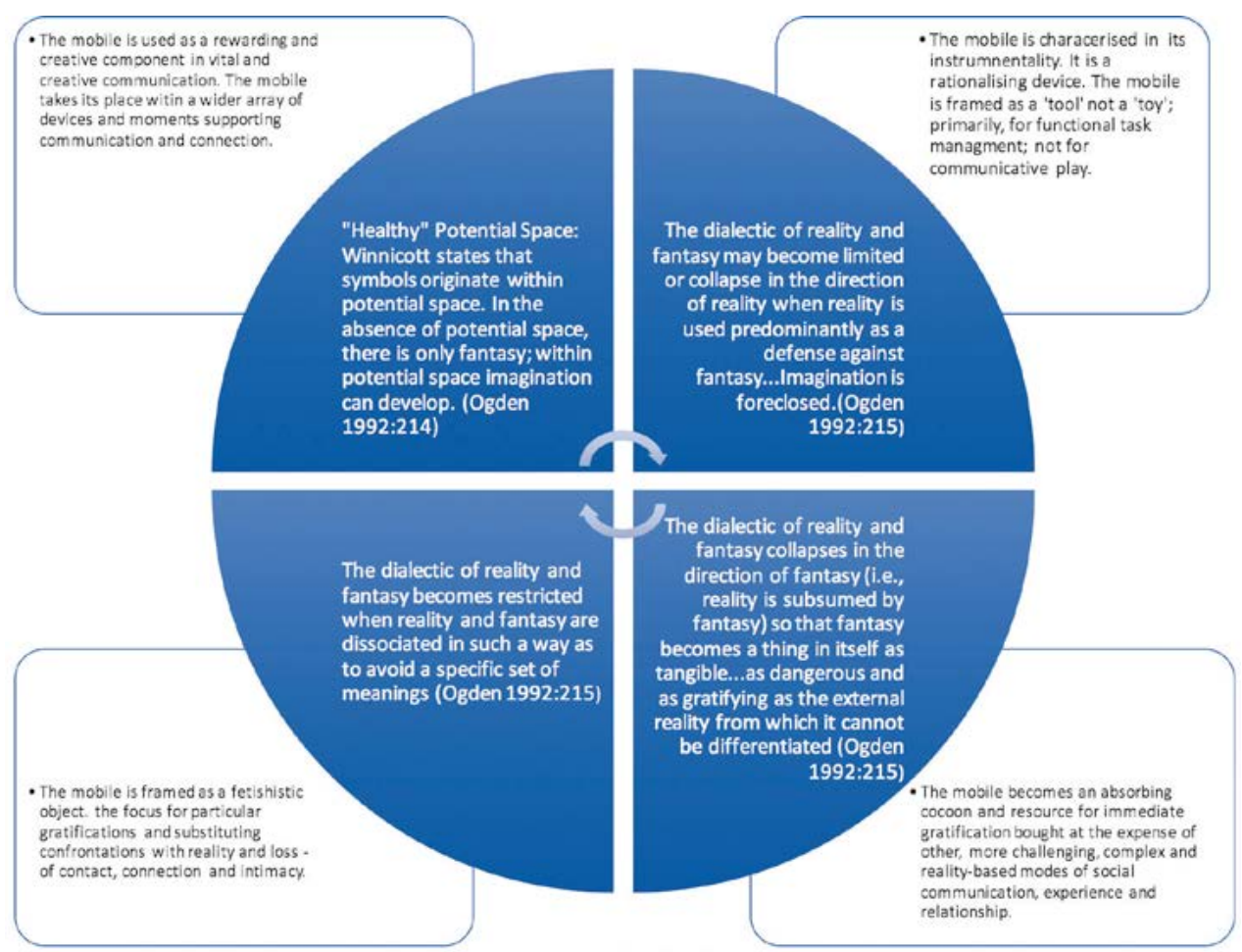

Figure 1.0 Pathologies of potential space evoked in discourses around mobile phones. 
We suggest that the mobile, and critical reflection upon its meaning and use can be framed within the terms of these characteristic pathologies, which we will present and discuss in detail below.

\section{1. Disturbance: Collapse into Fantasy}

Ogden's first "disturbance" is set out as follows: "The dialectic of reality and fantasy collapses in the direction of fantasy (i.e. reality is subsumed by fantasy) so that fantasy becomes a thing in itself" (Ogden, 1992: 229).

By way of illustrating this disturbance in relation to the mobile, we might think of the use of the phone as a kind of cocoon, as identified by Mizuko Ito et al. (2009).

"Cocoons are micro-places built through private, individually controlled infrastructures, temporarily appropriating public space for personal use. [...] These cocoons also have specific temporal features, functioning as mechanisms for 'filling' or 'killing' in-between time when people are inhabiting or moving through places within where they are not interested in fully engaging." (Ito et al., in Ling, 2009: 74)

This idea of the phone affording a fantasy "cocoon" or fantasy bubble is a frequent feature within discourses around mobility - the mobile virtual bubble 'becoming' the "real" world and amplifying solipsistic involvements. In contrast to engagements with other materialities, the mobile, because of its intimate proximity and animate character, can be experienced in a more seamless fashion as being, in some sense, part of the self. It can be viewed as facilitating the creative entanglement of subject and object and of inner and outer worlds. And yet, this merging with the object is sometimes viewed negatively as creating or amplifying a privatised, self-obsessed mode of existence (Music, 2014; Abraham, Pocheptsova \& Ferraro, 2012). This seems to be affirmed by Konrath, O'Brien, and Hsing (2016), who note that declines in college students' empathy coincided with the rise of social media and mobile phone usage.

The above accounts propose a form of "digital narcissism" (Bainbridge $\&$ Yates, 2014) and affirm Sherry Turkle's (2011a) well known suggestion that in a digital age, we are all "alone together". The superficial and narcissistic dimensions of one's relationship to the mobile phone in this context is anticipated in Frederic Jameson's (1991) work, which highlights superficial and "depthless" aspects of postmodern culture, a critique, which as we discuss below, remains 
influential within cultural studies' approaches to the mobile phone and digital culture more widely.

\section{2. Disturbance: Collapse into Reality}

Ogden's second disturbance is characterised in these terms: "The dialectic of reality and fantasy may become limited or collapse in the direction of reality when reality is used predominantly as a defense against fantasy... Imagination is foreclosed" (Ogden, 1992: 229).

This disturbance finds its actualization in relation to the mobile in scenarios when its use becomes radically instrumental. Thinking about and experiencing the array of communicative possibilities afforded by the mobile is then supplanted by a restricted and restricting sense of its rational functionality. There is a closing down or an inhibition in the use of some mobile potentials. Here, we may think, also, of the self-critique, or censorships, that become attached to some forms of mobile use, those that restrict the desire to explore new spaces or "dangerous" uses - and are defended against by an appeal to "real" communications or environments. The phone is apprehended primarily as a functional thing in itself rather than a means of connection and human communication or intimacy. The mobile phone becomes (in imagination or reflecting real arrangements in some cases) overwhelmingly a "work" object rather than a space for "playful" engagement. Anxieties about mixing work and leisure-play related usage can become exaggerated. Owning dual or multiple mobiles is a means to manage such anxiety, with some practical developments designed to institute a formal division between the playful-expansive as opposed to the work-a-dayinstrumental aspects of the phone (Metz, 2015). Such anxieties are sometimes expressed in terms of phone security (Abrahams, 2014).

We might also think here of non-use - as in the distrust of phones and apprehensions about "going mobile" in respect of intimate aspects of life (Davidson, 2013). For some, mobiles stand simply as practical objects, transactional in use, and thought about, primarily in the frames of data plans and call charges. But the mobile is placed within boundaries set, to a degree, against intimacy and with suspicions about the quality or authenticity of mobile intersubjective life. In extreme instances, the mobile becomes implicated in a feeling of "switching off" and, in psychosocial terms, becomes the objective correlative of a sense of disconnection. 


\section{3. Disturbance: Avoiding Specific Meanings}

A third disturbance in the dynamics of potential space is described by Ogden as follows: "The dialectic of reality and fantasy becomes restricted when reality and fantasy are disassociated in such a way as to avoid a specific set of meanings, e.g., the 'splitting of the ego' in fetishism" (Ogden, 1992: 230).

Again, mobiles, and talk about mobiles, can remind us of such patterns, for instance in the recognition and misrecognition of intimacy, within which the mobile can become implicated. Jukka Jouhki (2009) notes the blend of psychological and somatic attachment and its fetishistic character, highlighting the 'haptic' aspects of mobile experience. If we continue to further analyse the haptic quality of the bond, the device could be viewed as a modern day magical fetish. The mobile in all its rewarding tactility and controlled aesthetic frames becomes the place where excitation and apprehension (erotic and intimate) can be experienced and shared (e.g. via sexting and photography (Drouin \& Landgraff, 2012)) at the expense of other connections and channels. The risk evoked is that some degree of the experience of real, intimate, messy and risky human relating is foreclosed in favour of a fixation privileging the mobile screen.

In a more technical form of fetishism that echoes Menzies-Lyth's (1988) work on social defences against anxiety, research on medics' use of mobiles indicates the powerful-extensional role the mobile can play, becoming a repository for medical knowledge and, as an extension of medical training, a support for medical decision-making. It is even a convenient instrument for medical testing. In the same way that the stethoscope has traditionally been both an extension of the doctor's ear and a symbol of the doctor's knowledge (of data gathering and interpretation), the mobile phone represents a far more potent extension of the physician's senses and learning. It becomes a new interface with the world under investigation at the same time as it helps to establish a relationship with the dynamic storehouse of medical knowledge and protocol. The risk is that the mobile interface dehumanises the matrix of care afforded by the doctor, rather than enhancing it.

What connects these evaluations of the mobile as pathological is that they propose and seek to help clarify a variety of forms of disturbed psychosocial attachment. Ogden (1992: 224-232) draws on Hannah Segal's (1957/1990) notion of "Symbolic Equation", which implies the negation of "thirdness" and a capacity to experience psychological complexity that such pathologies of po- 
tential space entail. ${ }^{13}$ In commentary and casual reflection the mobile serves as a powerful metaphor and metonym for thinking about wider and more deepseated anxieties derived from emergent, complex and disruptive socialities. However, in some instances the metaphor or metonym becomes overpowering - and the mobile is not held in mind but demonised as a cultural 'bad object'.

"With limited capacity to distinguish symbol and symbolized, that which is perceived is unmediated by subjectivity (a sense of oneself as creator of meanings). The upshot is that perceptions carry with them an impersonal imperative for action and must be gotten rid of, clung to, concealed, hidden from, put into someone else, worshipped, shattered, etc. What the person cannot do is understand." (Ogden 1992: 217)

Cultural reflections on the mobile certainly include and open up insightful analysis. These analyses are energised to varying degrees by more primitive anxiousness. Such reflections reframe the mobile, as we seek to understand its complex materiality and significance and re-produce it as an object, variously, for "worship", "clinging", "rejection" and "concealment".

\section{Discussion: Mobile Objects in Culture}

From an object relations perspective, many of the negative readings of the mobile phone's cultural effects that we have presented, evoke a state of mind that is unable to mourn and think about the losses of late modernity associated with the rapid transformations that have accompanied the evolution of new technologies and the greater mobility and also instability that such technological change represents. It is easy to see the mobile at the vanguard of such changes and it is not surprising, therefore, that it becomes framed as both a catalyst and cause of increasing disturbance.

The unthinking repetitive use of the mobile, which is often referred to as an "addiction" in popular discourse and which is echoed in the pathologies of attachment discussed above, is also alluded to in Cultural Studies literature about the mobile, although it is not referred to explicitly in psychoanalytic terms. And

\footnotetext{
${ }^{13}$ Segal (1990) distinguishes between "symbol formation proper" and "symbolic equation", noting the distinction between relations to symbols as supporting interpretive meaning-making (i.e. understanding that this symbol might stand for that referent in this context), versus an experience of symbolism that concretely equates the symbol with the thing it seems to stand for, i.e. this symbol is the thing referred to. For instance, one might reasonably say my mobile is a representation of my friendships, but, in a (mad) panic, feel, when a phone is lost, that we have (actually) lost all our friends.
} 
yet, descriptions of the obsessional attraction and repeated use of the mobile by some cultural studies commentators seem to describe an unmediated need rather than an active desire for the object. For example, Mark Fisher describes the "demands of the digital" and links the mobile phone's appeal to the hedonistic world of internet pornography and Viagra as the related modern drug of choice, because "they dispense with seduction and aim directly at pleasure" (2009: 178). ${ }^{14}$ Citing Fredric Jameson's (1991) critique of postmodernism as characterised by a vacuous recycling of the past, Fisher says that the communicational intrusions of 21 st century digital media and the smart technology of mobile phones demand that we "remain in constant touch" (Agar, 2004). Fisher looks back at the Walkman, which was once used as an object of escape and he contrasts it with the all-consuming digitally induced instant pleasures of the mobile. Fisher says that we experience a "digital realm", representing a "superficial ....newness" (2009: 229). At the same time, we use the phone as a way to forget that we are stuck within a temporary zone in which culture recycles the past, always engaged but never connected.

Cultural Studies privileges an account of contemporary digital culture that cannot process the past and move on. Instead, it perpetuates a culture of pastiche and a faux mode of "nostalgia", as Jameson (1991) once said, and the current newest digital technology becomes a way of "refurbishing the old" (Fisher, 2014: 13). Here, it is argued that the digital realm of the mobile and our relationship to it articulates a mode of pathology that manifests a sense of repetition and alienation. In contrast to the relational possibilities of smart phone technology, the mobile is viewed here negatively as a symptom of neoliberalism, which as a cultural formation is also bound up with the end of history as a potential space for meaningful change. The repetitive use of the mobile echoes the stuckness of that wider cultural system and its use becomes a way to shore up a self that cannot mourn or let go of the past. The pathologies of potential space in this context are thus related to fetishism, obsession and a wish to revisit a version of the past that functions as a means to ward off that which cannot be let go or symbolised.

\footnotetext{
${ }^{14}$ We learnt of the sad news of Mark Fisher's recent death after this article had gone to press, The authors wish to acknowledge the valuable thought-provoking contributions of Mark Fisher to the field of Cultural Studies and to the analysis of shifting technological and cultural formations. His insights into the social and political costs of cultural disruption have influenced and inspired many important interventions in the study of the contemporary moment - not least in relation to understanding the mobile phone.
} 


\section{Finding New Spaces for Intimacy and Connection}

There is a recurrent tendency in the analyses of mobile culture to articulate concerns in which the mobile becomes an indexical symbol of deeper anxieties about the experience of disconnection and loss within the late modern world. Such an account is a legitimate response to the mobile phone in a neoliberal age where the practices and values of instrumentalism disembed and redistribute affective and intimate relationships in both space and time and where the mobile seems to offer an insufficient substitute for other intimacies that have been lost or re-routed. Nevertheless, such a response risks overstating the negative impact of mobile technology in the contemporary era. The tantalising qualities of the mobile evoke desires for meaningful connection as represented in those discursive domains where more optimistic accounts of the mobile connote a more complex, multi-layered relationship between self, object and the outside world. In such contexts, it seems that the mobile enables an experience of intimacy to emerge that escapes the narcissistic impulse for mastery that is often said to shape communication today (Turkle, 2011). Instead, the new modes of intimacy that are implied here sit well with Winnicott's (1971) relational paradigm of transitional phenomena, which emphasises the process of meaningful and life-enhancing interaction with an/other. Ogden's theoretical assumptions regarding the dialectics of potential space can be applied in this context insofar that the mobile functions as a bridge between Ogden's notion of "the interpreting subject" and the M/other in which the triangular dynamics of symbolisation operate and occur (1992: 213).

This relational model of communication taps into an alternative notion of the mobile subject where the negotiation of time and space are said to play a key role in reflexive subjectivity and in forming relationships with others (Tachi, Kitner \& Crawford, 2012). From this perspective, the experience of the mobile opens up new spaces for creativity and the extension of the self, in which the old boundaries of time, space and otherness can be transcended in order to create new intimacies and discover new ways of relating with one another across media platforms. This more nuanced account of subjectivity and communication is, in part, analogous to Ogden's developmental schema of the child's "transformation of unity into thirdness" (Ogden, 1992: 216) whereby the child moves from a state of being merged with the mother into one of separation, when the experience of thirdness emerges. Yet, as Ogden says, the experience of separa- 
tion is not a fixed state but rather an on-going, dialectic process, in which the child (and later the adult) never separates completely from the first object but instead reworks that relationship in different contexts.

The temporal and spatial aspects of using the mobile in a fast-moving globalised world thus allow the development of new conceptions of the reflexive, "mobile self" (Elliott \& Urry, 2010). From this perspective, the mobile phone functions as a portable extension of that self, shaped by a "technological unconscious" that enables the subject to negotiate "the productive possibilities" of an international "networked world" (Elliott \& Urry, 2010). In this scenario, the "productive possibilities" of a networked environment can be seen as analogous to Winnicott and Ogden's model of the facilitating good mother. Here, one can argue that when internalising the possibilities that she (the mother) represents, the interpreting subject (the user of the mobile) moves in a fluid fashion between oedipal and pre-oedipal modes of being, thereby challenging the duality that has hitherto sustained a split gendered mode of relating to the world. The mobile can thus been seen as both contributing to and functioning within a nexus of psychosocial and technological relations that unsettle older, vertical structures of selfhood and communication and instead enable horizontal modes of relating where the dialectic of potential space can operate.

\section{Conclusion}

Throughout this article, we have argued that Winnicott's theories of transitional phenomena take on new meaning in a networked society where the experience of mediatisation and the fluid processes of communication that stem from it become bound up with the relational dynamics of everyday life. The mobile stands as a useful figuration of the "transitional object" - a specific instantiation of the idea of transitional phenomena. Winnicott's writings bring to life the significance of play for the early development of subjectivity and also for the capacity to play with objects and ideas in later life. The deformations and difficulties associated with transitional objects and potential spaces allow us to extend the analogy with mobiles to incorporate an understanding of the vicissitudes of mobile cultures, which include: addictions, anxieties about surveillance, cultural distraction, and the seductions and dangers of the "exposure" of self through the use of the mobile-as-subjective-object. Taking an object 
relations perspective allows us to draw on such ideas in order to unpack the relational dynamics of the mobile phone and its uses.

Our relationship to external objects such as the mobile is always psychological, always psychosocial (Bainbridge \& Yates, 2012, 2014). In other words, our relationship to the mobile is shaped continually by the experience of potential space and of coming into being and the processes of imagination, fantasy, emotion and identification. As an object of both pleasure and frustration, the symbolism of the mobile phone is significant because it is evocative of a deeply held wish for meaningful connection within the precarious setting of the late modern world. 


\section{References}

Abraham, A. T., Pocheptsova, A. \& Ferraro, R. (2012). The Effect of Mobile Phone Use on Prosocial Behavior. Unpublished manuscript, University of Maryland.

Abrahams, R. (2014). The Two-phone Solution Doubles the Pain, Not the Pleasure. Huffington Post, 3 April 2014. Accessed 30. 09. 2016. URL: http://www.huffingtonpost.com/rebecca-abrahams/the-two-phone-solution-do_b_5085527.html.

Agar, J. (2004). Constant Touch: A Global History of the Mobile Phone. Cambridge: Icon Books.

Alleyne, R. (2012). Mobile Phone Addiction Ruining Relationships. The Telegraph, 30 November 2012. Accessed 16. 11. 2016. URL: http://www.telegraph.co.uk/technology/news/9714616/Mobile-phone-addiction-ruiningrelationships.html.

Bainbridge, C. \& Yates, C. (2012). Introduction to Special Issue on Media and the Inner World: New Perspectives on Psychoanalysis and Popular Culture. Psychoanalysis, Culture \& Society, 17(2): 113-119.

Bainbridge, C. \& Yates, C. (2014). Introduction: Psycho-cultural Approaches to Emotion, Media and Popular Culture. In Bainbridge, C. \& Yates, C. (eds.), Media and the Inner World, Psycho-Cultural Approaches to Emotion, Media and Popular Culture (pp. 1-19). Basingstoke: Palgrave Macmillan.

Balick, A. (2016). Checking Your Smartphone Again? It's an Object of Emotional Supply. Dr Aaron Balick Website. Accessed 16. 12. 2016. URL: http:// www.aaronbalick.com/blog/checking-your-smartphone-again-its-an-objectof-emotional-supply/.

Balick, A. (2013). The Psychodynamics of Social Networking. London: Karnac Books.

Bauman, Z. (2007). Liquid Times: Living in an Age of Uncertainty. Cambridge: Polity Press.

Beck, U. (1992). Risk Society: Towards a New Modernity. London: Sage.

Bingham, J. (2012). Mobile Addict Parents Guilty of Child 'Neglect' Warns Psychologist. The Telegraph, 22 May 2012. Accessed 13. 06. 2016. URL: 
http://www.telegraph.co.uk/women/mother-tongue/9280194/Mobileaddict-parents-guilty-of-child-neglect-warns-psychologist.html.

Bollas, C. (2009). The Evocative Object World. London: Routledge.

Bowlby, J. (2008) Attachment and Loss: Separation: Anxiety and Anger. London: Basic Books.

Castells, M. (2007). Communication, Power and Counter-power in the Network Society. International Journal of Communication, 1(1): 238-266.

Clark, A. (2015). 'Mobile Phones have Changed the World for Better or Worse', The Guardian 3 January, Accessed 02. 01. 2017. URL: https:// www.theguardian.com/commentisfree/2015/jan/03/mobile-phones-havechanged-world-for-better-or-worse.

Daily Mail Reporter (2009). How Women Love Their Mobile Phones... More than Their Boyfriends. Daily Mail On Line, 20 December 2012. Accessed 02. 01. 2017. URL: http://www.dailymail.co.uk/femail/article-1239182/ How-women-love-mobile-phones--boyfriends.html.

Davidson, M. (2013). It's Time to Switch off Your Mobile and Set Yourself Free. The Telegraph, 28 January 2013. Accessed 31. 12. 2016. URL: http:// www.telegraph.co.uk/technology/9831913/Its-time-to-switch-off-yourmobile-and-set-yourself-free.html.

Díaz, L. \& Ekman, U. (2011). Introduction to Mobile Ubiquity in Public and Private Spaces. Digital Creativity, 22(3): 127-133.

Drouin, M. \& Landgraff, C. (2012). Texting, Sexting and Attachment in College Students Romantic Relationships. Computers in Human Behavior, 28 (2): 444-449.

Du Gay, P., Hall, S., Janes, L., Koed Madsen, S., Mackay, H. \& Negus, K. (2013). Doing Cultural Studies: The Story of the Sony Walkman (revised edition). Milton Keynes: Sage Books.

Eco, U. (2014). Foreword - Truth and the Mobile Phone. In Ferraris, M. \& De Sanctis, S. (trans.) Where Are You? An Ontology of the Cell Phone. New York: Fordham UP.

Elliot, A. \& Urry, J. (2010). Mobile Lives. London: Routledge.

Elliott, A. (1996). Subject to Ourselves: Social Theory, Psychoanalysis and Postmodernity. Cambridge: Polity Press. 
Fisher, M. (2009). Capitalist Realism. London: Zero Books.

Fisher, M. (2014). Ghosts of my Life: Writings on Depression, Haunting and Lost Futures. New York: Zero Books.

Fortunati, L. \& Taipale, S. (2014). The Advanced Use of Mobile Phones in Five European Countries. The British Journal of Sociology, 65(2): 317-337.

Fortunati, L. (2002). The Mobile Phone: Towards New Categories and Social Relations. Information, Communication \& Society, 5(4): 513-528.

Garber, M. (2012). Just Thinking about Your Cell Phone Makes You More Selfish. 21 February 2012. Accessed 14. 11. 2016. URL: http://www.theatlantic.com/technology/archive/2012/02/just-thinking-about-your-cell-phonemakes-you-more-selfish/253269/.

Giroux, H. (2015). Selfie Culture at the Intersection of the Corporate and the Surveillance States. Counterpunch, 6 February. Accessed 16. 6. 2016. URL: http://www.counterpunch.org/2015/02/06/selfie-culture-at-the-intersection-of-the-corporate-and-the-surveillance-states/.

Heffernan, M. (2013). Why Putting Down Yourself Will Help Your Business.26 August 2013. Accessed 20. 12. 2016. URL: http://www.inc.com/ margaret-heffernan/put-the-cell-phone-away.html.

Hills, M. (2007). Essential Tensions: Winnicottian Object-relations in the Media Sociology of Roger Silverstone. International Journal of Communication, 1(1): 37-48.

Hjorth, L. \& Lim, S. S. (2012). Mobile Intimacy in an Age of Affective Mobile Media. Feminist Media Studies, 12(4): 447-484.

Hjorth, L., Burgess, J. \& Richardson, I. (2012). Studying Mobile Media: Cultural Technologies, Mobile Communication, and the iPhone. New York: Routledge.

Ito, M., Okabe, D. \& Anderson, K. (2009). Portable Objects in Three Global Cities: The Personalization of Urban Places. In Ling, R. \& Campbell, S. (eds.), The Reconstruction of Space \& Time through Mobile Communication Practices (pp. 67-88). New Brunswick: Transaction Books.

Jameson, F. (1991). Postmodernism, or, the Cultural Logic of Late Capitalism. Durham: Duke University Press. 
Johnson, D. (2010). Love: Bondage or Liberation? A Psychological Exploration of the Meaning. London: Karnac Books.

Jouhki, J. (2009). A Modern Fetish: The Value of the Mobile Phone in South Korean Culture. Proceedings of ICT, Society and Human Beings 2009: 121128.

Kahr, B. (2016). Tea with Winnicott. London: Karnac Books.

Kahr, B. (1996) D. W. Winnicott, A Biographical Portrait. London: Karnac Books.

Kang, H. Y. \& Son, C. (2009) Development and Validation of the Mobile Phone Addiction Scale for Adolescents. Korean Journal of Health Psychology, 14(3): 497-510.

Klein, M. (1937/1988). Love Guilt and Reparation. In Klein, M. (ed.), Love, Guilt and Reparation (pp. 306-344). London: Virago Press.

Klein, M. (1946/1988). Notes on Some Schizoid Mechanisms. In Klein, M. (ed.), Envy and Gratitude and Other Works 1946-1963 (pp. 1-25) London: Virago Press.

Knorr-Cetina, K. (2001). Objectual Practice. In Schatzki, T. R., Knorr-Cetina, K. \& Von Savigny, E. (eds.), The Practice Turn In Contemporary Theory (pp. 184-198). London: Routledge.

Konrath, S. H., O’Brien, E. H. \& Hsing, C. (2016). Changes in Dispositional Empathy in American College Students over Time: A Meta-analysis. Personality and Social Psychology Review, 15(2): 180-198.

Kullman, K. (2010). Transitional Geographies: Making Mobile Children. Social \& Cultural Geography, 11(8): 829-846.

Kuhn, A. (ed.) (2013). Little Madnesses. London: I.B. Taurus.

Kunst, J. (2012). Do You Have a Love/hate Relationship with Your Phone? Psychology Today. Accessed 13. 6. 2016. URL: https:/www.psychologytoday. $\mathrm{com} / \mathrm{blog} /$ headshrinkers-guide-the-galaxy/201204/do-you-have-lovehaterelationship-your-phone.

Latour, B. (2007). Reassembling the Social. Oxford: Oxford University Press.

Ling, R. (2007). Children, Youth and Mobile Communication. Journal of Children and Media, 1(13): 60-67. 
McLuhan, M. (1964) Understanding Media: The Extension of Man. New York: McGgraw-Hill.

Menzies-Lyth, I. E. P. (ed.) (1988). Containing Anxiety in Institutions: Selected Essays, Volume 1. London: Free Association Books.

Metz, C. (2015). How Amazon, Google, and Facebook will bring down Telcos. WIRED. Accessed 31. 12. 2016. URL: https://www.wired.com/2015/02/ googles-android-work-gives-phone-split-personality/.

Music, G. (2014). The Buzz Trap: Speeded-up Lives, Distractedness, Impulsiveness and Decreasing Empathy. Psychodynamic Practice, 20(3): 228-249.

Ogden, T. H. (1992). The Matrix of the Mind: Object Relations and the Psychoanalytic Dialogue. London: Karnac Books.

Ribak, R. (2009). Remote Control, Umbilical Cord and beyond: The Mobile Phone as a Transitional Object. British Journal of Developmental Psychology, 27(1): 183-196.

Richards, B. (2007). Emotional Governance: Politics, Media and Terror. Basingstoke: Palgrave Macmillan.

Royal Mail (2008). Lost without Your Mobile? Sounds Like a Case of Nomophobia. Accessed 24. 11. 2016. URL: http://www.royalmailgroup.com/cy/ lost-without-your-mobile-sounds-case-nomo-phobia.

Richardson, I. (2012). Studying Mobile Media: Cultural Technologies, Mobile Communication, and the iPhone. New York: Routledge.

Riesman, D. (1950). The Lonely Crowd: A Study of the Changing American Character, by David Riesman. In Collaboration with Reuel Denney and Nathan Glazer. New Haven: Yale University Press.

Rodman, F. R. (2005) Preface to the Routledge Classics Edition. In Winnicott, D. W. (ed.), Playing and Reality (pp. ix-xv). London: Routledge.

Segal, H. (1957/1990). Dream, Phantasy, and Art. London: Tavistock/Routledge.

Serrano-Puche, J. (2015). Emotions and Digital Technologies, Mapping the Field of Research in Media Studies. Media and LSE Working Paper 33, Accessed 12. 7. 2016. URL: www.lse.ac.uk/media@lse/research/mediaWorkingPapers/pdf/WP33-FINAL.pdf. 
Silverstone, R. \& Hirsch, E. (eds.) (1992). Consuming Technologies. London: Routledge.

Spelman, M. B. \& Thomson-Salo, F. (eds.) (2014). The Winnicott Tradition:

Lines of Development-Evolution of Theory and Practice Over the Decades. London: Karnac Books.

Tacchi, J., Kitner, K. R. \& Crawford, K. (2012). Meaningful Mobility, Gender, Development and Mobile Phones. Feminist Media Studies, 12(4): 528-537. Turkle, S. (2011a). Alone Together: Why we Expect More From Technology and Less From Each Other. New York: Basic Books.

Turkle, S. (2011b). Evocative Objects: Things We Think With. Cambridge, Mass.: MIT Press.

Whitty, M. T. \& Carr, A. N. (2003). Cyberspace as Potential Space: Considering the Web as a Playground to Cyber-flirt. Human Relations, 56(7): 869-891.

Winnicott, D. W. (1958) The Capacity to Be Alone. The International Journal of Psychoanalysis, 39: 416-420.

Winnicott, D. W. (1963). The Development of the Capacity for Concern. Bull. Menninger Clin., 27: 167-176.

Winnicott, D. W. (1971). Playing and Reality. London: Tavistock Publications.

Woodward, I. (2011). Towards and Object Relations Theory of Consumerism: The Aesthetics of Desire and the Unfolding Materiality of Social Life. Journal of Consumer Culture, 11(3): 366-384.

\section{Acknowledgements}

We would like to express our thanks to our BU colleague Christopher Miles for contributing to earlier drafts of this article. We would also like to thank the anonymous journal reviewers for reading through and providing very helpful comments on the content of the article. 
Framing the Mobile Phone:

lain MacRury

The Psychopathologies of an Everyday Object

Candida Yates 